74

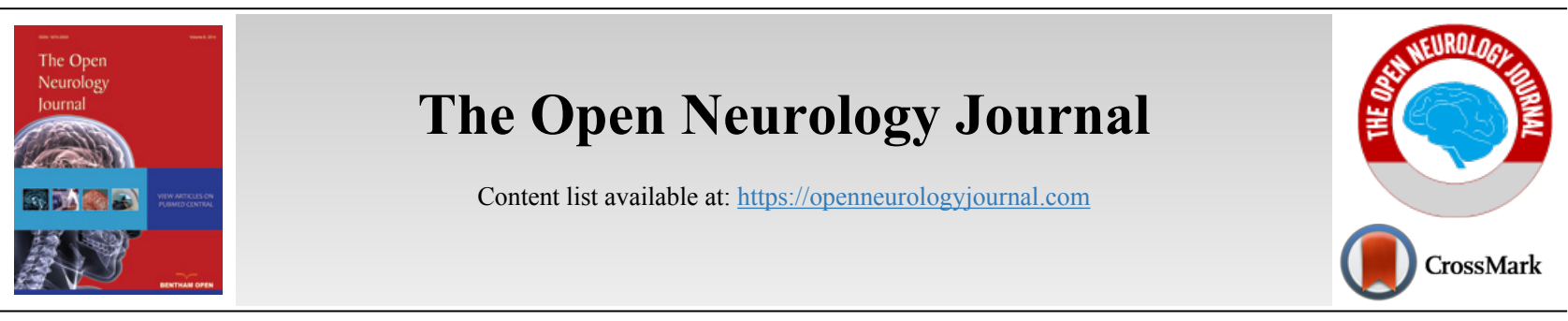

REVIEW ARTICLE

\title{
Short-Lasting Unilateral Neuralgiform Headache Attacks with Conjunctival Injection and Tearing (SUNCT) Status Like Condition: A Rare Case Report and Review of the Literature.
}

Jayanti K Gurumukhani ${ }^{1}$, Dhruvkumar M. Patel ${ }^{2}$, Mukundkumar V. Patel ${ }^{3, *}$, Maitri M. Patel ${ }^{4}$, Anand V Patel ${ }^{5}$ and Suyog Y Patel $^{6}$

\author{
${ }^{1}$ Jay Neurology and physiotherapy clinic, Bhavnagar, India \\ ${ }^{2} Z y d u s$ Medical College, and Hospital, Dahod, India \\ ${ }^{3} Z y d u s$ Medical College and Hospital, Dahod, India \\ ${ }^{4}$ GCS Medical College and Hospital Ahmedabad, India \\ ${ }^{5}$ University of Texas Medical Branch, Galveston, TXUSA \\ ${ }^{6}$ B.J. Medical College, Ahmedabad, India
}

\begin{abstract}
:
Background:

SUNCT (short-lasting unilateral neuralgiform headache attacks with conjunctival injection and tearing) is rare trigeminal autonomic cephalgia characterized by recurrent, brief, excruciating unilateral, intermittent headache paroxysms over orbital, frontal or temporal region occurring multiple times per day and it can rarely present as "SUNCTstatus like condition" (SSLC).

Case Report:

A 28-year old male with a history of SUNCT headache for 6 months presented with left forehead stabs lasting for 30 seconds with a frequency of 40-45 episodes per hour for three days followed by infective gastroenteritis. His neurological examination was normal, except left-sided ptosis, tearing, and conjunctival injection. His MRI brain with contrast, MR angiography, and laboratory investigations were unremarkable except mild hypokalemia. He was treated with intravenous fluids, potassium replacement, and high dose methylprednisolone along with an escalated dose of carbamazepine.

\section{Review and Conclusion:}

We have reviewed the previously reported seven cases and our case of SSLC. Female: Male ratio was 3:1and the mean age was 40.87 years. Three patients responded to high dose steroids and three to lignocaine along with rapid escalation or change of anticonvulsant drugs. One case responded to the high dose of lamotrigine, and in a pregnant lady, the pain subsided only after the termination of the pregnancy. One case was secondary to multiple sclerosis, while the rest of seven were primary episodic SSLC. The condition is highly disabling, and the treatment with steroids or lignocaine, along with the rapid escalation of preventive drugs, can provide long-lasting relief
\end{abstract}

Keywords: SUNCT, Short-lasting unilateral neuralgiform headache, SUNCT status like condition, Headache, Methylprednisolone, Lidocaine, Carbamazepine.

Received: April 01, 2020

Revised: June 10, 2020

Accepted: June 15, 2020

\section{INTRODUCTION}

The International Classification of Headache Disorders 3rd edition (ICHD-3) guidelines have defined "trigeminal autonomic cephalgias" (TAC) as a group of primary headache disorders characterized by brief episodes of severe unilateral hea-

\footnotetext{
* Address correspondence to this author at the Associate professor in medicine
} Zydus Medical College and Hospital, Dahod, Gujarat, India;

Tel: +919909013760 E-mail: drmukundvpatel123@yahoo.co.in dache in the distribution territory of the trigeminal nerve, accompanied by ipsilateral cranial parasympathetic autonomic features $[1,2]$. TACs include cluster headache, paroxysmal hemicrania, short-lasting neuralgiform headache attacks, and hemicrania continua [ 1 - 4]. These conditions are distinguished by their attack duration and frequency, as well as response to treatment. The short-lasting neuralgiform unilateral headache attacks are of two subtypes: SUNCT (short-lasting unilateral 
neuralgiform headache attacks with conjunctival injection and tearing) and the SUNA (short-lasting unilateral neuralgiform headache attacks with cranial autonomic symptoms) $[1,2]$. In SUNCT, conjunctival injection and tearing both are mandatory autonomic symptoms, while in SUNA, either conjunctival injection or tearing or any one of the cephalgic autonomic features is present [1 - 4].

SUNCT is characterized by a stab or series of stabs, of moderate to severe intensity, located at the orbital, periorbital, or temporal region with one or more attacks per day lasting 1-600 seconds with at least 20 documented episodes [1 - 4]. Functional imaging studies of the brain have suggested SUNCT as a result of trigeminal parasympathetic neural track activation due to a variety of causes like demyelination or inflammation [5]. It is commonly seen in the age group of 35 to 65 years with a mean age of 48 years $[6,7]$. This term "SUNCT status like condition"(SSLC) is not defined exactly, but most of the authors have agreed to the SUNCT presentation with a frequency of more than 30 per hour or continuous stabs of saw tooth pattern with minimum or no pain-free interval in between the attacks better half a day or sudden increase in the frequency of attacks requiring hospitalization or interfering with activities of daily livings [6, 7]. Anticonvulsant drugs, such as lamotrigine and Carbamazepine (CBZ) are effective for the treatment of SUNCT [6, 7]. However, the SSLC is resistant to these oral therapies and parenteral lignocaine or high dose methylprednisolone (MP) that are the mainstay of the treatment. Differentiation of SSLC from the SUNCT and trigeminal neuralgia is challenging due to many overlapping features $[6,7]$.

We report a unique case of a young male, who was presented with SSLC. We have also reviewed the previously reported cases and our case of SSLC in this review article.

\section{CASE REPORT}

A 28-year old male presented with a 3 days history of left forehead stabbing pain. The pain was excruciating (visual analog score (VAS) 9/10), electric current like with a series of stabs lasting 30 seconds with a frequency of about $40-45$ per hour. He had mild to moderate background pain in between severe episodes of saw tooth pattern stabs for the last three days. The pain was exacerbated on touching and combing hairs. This was associated with left eye redness with discharge and mild left ptosis. He had a history of infective gastroenteritis before 4 days and was treated with intravenous fluids, ceftriaxone, and ondansetron for 24 hours. He was not tolerating orally and had not consumed CBZ for the last three days.

On presentation, he was mildly dehydrated and had orthostatic hypotension with tachycardia. His cardiorespiratory evaluation unrevealed any abnormality, and the abdomen was soft with normal peristalsis. Neurological examination was unrevealing except that he had left eye conjunctival injection associated with tearing and mild ptosis. Six months before also he had similar episodes of excruciating pain (VAS:9/10) over his left forehead lasting 20-30 seconds, about 6-8 episodes per day with left eye redness, tearing, and mild ptosis. These episodes, which lasted for two weeks, were effectively treated with CBZ and a short course of oral steroids. His MRI (magnetic resonance imaging) of the brain with contrast and angiography on both the occasions (6 months back and now) were unremarkable. His hemogram, renal function tests, liver function tests, blood sugar, and serum electrolytes were normal except low serum potassium level of $3.1 \mathrm{mEq} / \mathrm{L}$ (Normal range: 3.6- $5.5 \mathrm{mEq} / \mathrm{L}$ ).

He was treated with intravenous (IV) normal saline and potassium chloride infusion for correction of dehydration and hypokalemia. Simultaneously, IV methylprednisolone $1 \mathrm{gm}$ diluted in $250 \mathrm{ml}$ normal saline was given daily for 3 days. This was followed by a gradually tapering dose of oral prednisolone starting with $1 \mathrm{mg} / \mathrm{kg} / \mathrm{day}$. The CBZ was gradually increased from $400 \mathrm{mg}$ to $1600 \mathrm{mg}$ daily over the next 4 days. There was a great reduction in the frequency and severity of symptoms in 3 days. He was also treated with indomethacin $150 \mathrm{mg}$ daily for 3 days. Since the patient was unable to tolerate this drug and therefore, he discontinued as no benefits were shown. He ultimately became symptom-free with CBZ and steroids after one week.

\section{DISCUSSION}

The main differential diagnosis of unilateral severe electric current like or stabbing pain over the forehead is "trigeminal neuralgia in V1 (ophthalmic division) distribution", "SUNCT" and "SSLC" (Table 1) [1, 2]. Our patient had a history of unilateral frontal stabs lasting for 30 seconds, associated with prominent conjunctival injection and tearing, without a refractory period and normal MRI brain 6 months back. This supports the diagnosis of primary episodic SUNCT as per the ICHD-3 guidelines [1, 2]. He now presented with unilateral short-lasting (30 seconds duration), recurrent episodes (40-45 per hour) of excruciating stabbing pain over his left forehead of 3 days. This was associated with conjunctival injection, lacrimation, and mild ptosis. He had background pain in between the episodes which were exacerbated by touching and combing hairs with no refractory period. All these findings favored the diagnosis of SSLC $[1,2]$. His repeat MRI brain was unremarkable favoring idiopathic SSLC. We treated our patient with IV-Methylprednisolone $1 \mathrm{gm}$ infusion daily for three days followed by oral prednisolone $1 \mathrm{mg} / \mathrm{kg}$ daily along with the rapid escalation of oral CBZ up to $1600 \mathrm{mg}$ in the next four days. The patient significantly improved in three days and became asymptomatic after 7 days. Since the headache subtype is of ultra-short duration, rapid-acting parenteral drugs having neuro-analgesic and anti-inflammatory properties are effective bridge therapy for escalating the dose of existing preventive drugs to the maximum recommended level [7,9].

\section{REVIEW OF THE LITERATURE}

SUNCT is a highly disabling condition affecting activities of daily living $[8,9]$. The exact pathophysiology of SUNCT is not known. However, previous studies suggested focal demyelination of the trigeminal tract as a peripheral mechanism and inflammation of the posterior hypothalamus as a central mechanism for SUNA/SUNCT [9 - 11]. If more than one cephalgic autonomic features are present as in SUNCT central neurological contribution is more responsible as compared to the peripheral mechanism, while in cases of a 
single autonomic feature as in SUNA peripheral neural contribution is significant $[3,5,12,13]$.

Previous studies have demonstrated analgesic, antihyperalgesic and anti-inflammatory properties of systemic lignocaine therapy [14 - 16]. Animal model studies have demonstrated the efficacy of systemic lignocaine by preventing depolarization of the nerve cell membrane, especially of inflamed and dysfunctional nerves by blocking active sodium channels [14 - 21]. The recommended dose of IV lignocaine is $2 \mathrm{mg} / \mathrm{kg}$ as an initial bolus followed by continuous infusion of $1-3 \mathrm{mg} / \mathrm{kg} /$ hour for 3 to 7 days. The drug has a narrow therapeutic window with a therapeutic plasma level 2.5-3.5 $\mathrm{ug} / \mathrm{ml}$. With plasma level of $>5.0 \mathrm{ug} / \mathrm{ml}$, central nervous side effects like sedation, lightheadedness, ataxia, visual disturbances, muscles twitching and finally coma occur, while at the plasma level $>10 \mathrm{ug} / \mathrm{ml}$, the cardiac side effects like sinus arrest, various atrioventricular blocks, tachyarrhythmias, and transient hypertension followed by hypotension are observed [14 - 21]. Hence the patient requires intensive care unit admission for IV lignocaine administration for cardiac monitoring.

High dose IV MP (500-1000 mg) daily for 3-5 days has potent anti-inflammatory and immunomodulatory actions and it is used extensively in many neurological conditions like multiple sclerosis acute spinal cord compression and cluster headaches unresponsive to conventional therapy [22 - 25]. It acts by modifications of cell activation, cytokine expression, reduction of inflammatory mediators, and T-cell apoptosis in the nervous system [26 - 28]. Most frequently reported adverse effects of short-course high dose steroids are hypertension, hyperglycemia, dyslipidemia, change in taste, facial flushing, generalized edema, skin rashes, abdominal pain, severe arthralgia, myalgia, insomnia, anorexia and psychological side effects like agitation and behavioral changes [29 - 32]. High dose MP injection should be given by slow IV infusion to prevent life-threatening hypokalemia [32, 33].

To the best of our knowledge, seven cases of SUNCT status like conditions have been reported to date and ours is the eighth case. Out of 8 cases, six were females and two were males (F: $\mathrm{M}=3: 1)$ with a mean age of 40.87 years. As per the literature, both lidocaine and/or high dose Methylprednisolone (MP) IV infusions along with the rapid escalation of preventive drugs are effective pharmacological options for the treatment of SSLC [3 - 5, 9]. In the literature search, three patients were treated with high dose steroids and three responded to parenteral lignocaine apart from rapid escalation or change of anticonvulsant drugs. In one pregnant patient, SSLC did not respond to opioid or NSAID analgesics, anticonvulsants or lignocaine, and subsided only after termination of the pregnancy. Only a single patient responded to high dose lamotrigine and supportive treatment. Since status like condition is more common in females and one case responded to termination of the pregnancy, it seems like hormonal factors are contributing to precipitation of SUNCT status in females. However, this postulation requires further large-scale studies to find exact pathophysiology and female preponderance. One case was secondary to multiple sclerosis, while the rest of seven were primary episodic SUNCT, who presented with "status like condition".

Table 1. Differentiating features of trigeminal neuralgia (V1), SUNCT, and SSLC.

\begin{tabular}{|l|l|l|l|}
\hline Character & $\begin{array}{l}\text { Trigeminal } \\
\text { Neuralgia (V1) }\end{array}$ & SUNCT & SSLC \\
\hline Duration in seconds & $1-120$ & $1-600$ & $1-600$ \\
\hline Frequencies/ Hour & $1-30$ & $1-30$ & $30-60$ \\
\hline Minimum episodes & Not defined & 20 & 360 \\
\hline $\begin{array}{l}\text { Conjunctival injection } \\
\text { and tearing }\end{array}$ & Rare \& mild & prominent & Prominent \\
\hline $\begin{array}{l}\text { Refractory period } \\
\text { between pain attacks }\end{array}$ & Present & Absent & Absent \\
\hline Inter-attack pain & uncommon & $\begin{array}{l}\text { Usually } \\
\text { Absent }\end{array}$ & $\begin{array}{l}\text { Usually } \\
\text { Present }\end{array}$ \\
\hline
\end{tabular}

injection and tearing, SSLC: SUNCT status like condition.

Bogorad et al. reported a case of a 61-year-old female, who presented with SSLC secondary to multiple sclerosis with demyelinating lesions of left trigeminal nucleus and tract [34]. She presented with a stabbing headache for a few seconds with a frequency of 30 episodes/hour for 48 hours. She responded to augmented doses of $\mathrm{CBZ}$ and steroids along with indomethacin. Montes et al reported 2 young female cases of SSLC [7]. The first case was a 26-year female, who presented with a stabbing headache with a frequency of 15-60 per hour and was resistant to indomethacin, ergots, and CBZ. She responded with MP $1 \mathrm{gm}$ IV infusion daily for 3 days followed by oral steroids along with an up titrated dose of CBZ to 1200 $\mathrm{mg}$ per day and was asymptomatic for more than a year [7]. The second patient, a 23-year female had 3-4 SUNCT attacks during the ovulation time. She presented with SSLC at the 8th week of gestation and was resistant to all the medication tried and the pain subsided only after termination of pregnancy [7]. Williams et al. reported 2 patients of SSLC [8]. The first case was a 22-year female with a 5-year history of SUNCT headache, who presented with frequent (25-35 per hour) stabs of 120 seconds for the last 3 days. She responded to an escalation of lamotrigine to $400 \mathrm{mg}$ daily [8]. The second case was a 47-year female with SUNCT of 28-year duration who presented with a headache frequency of 100-300/day and each episode lasting 5-10 seconds. She was treated with lignocaine $2 \mathrm{mg} / \mathrm{min}$ subcutaneously for 3 days along with lamotrigine $50 \mathrm{mg}$ daily as preventive therapy [8]. Matharu et al reported two cases of SSLC [35]. The first case was a 60 -year female with frequent (5-30/hour) electric shock-like pain over the right forehead of 10-30 seconds throughout the day. She was treated with lignocaine IV $1 \mathrm{mg} / \mathrm{min}$ for 7 days along with topiramate $150 \mathrm{mg}$ and CBZ 400mg daily as preventive drugs with complete recovery [35]. The second case was a 60 -year male, who presented with the rapid escalation of SUNCT attacks about 200-300 per day lasting for 5-60 seconds over left retroorbital and orbital regions. He was unable to eat or talk during the pain attacks. He responded to lignocaine IV $2 \mathrm{mg} / \mathrm{min}$ and topiramate $50 \mathrm{mg}$ daily as a preventive medicine [35]. Previously reported cases were due to missed doses of preventive anticonvulsant drugs or unknown reasons, while in our case apart from the missed doses of preventive drugs, dehydration and hypokalemia were possible triggers. Parenteral 
lignocaine or high dose MP is the mainstay treatment of SSLC but both the drugs are likely to precipitate life-threatening cardiac arrhythmias in the presence of hypokalemia. We have decided to use IV MP and it was challenging to correct serum potassium level and to simultaneously infuse MP injection.

\section{CONCLUSION}

SUNCT, a rare type of trigeminal autonomic cephalalgia, can occasionally present with a high frequency of stab attacks defined as "SUNCTstatus like condition". Timely diagnosis and treatment with high dose steroids or systemic lignocaine along with the rapid escalation of preventive drugs can provide long-lasting relief.

\section{AUTHORS' CONTRIBUTIONS}

All the authors have contributed equally to the management of the reported patient and preparation of the manuscript.

\section{INFORMED CONSENT}

The written consent was obtained from the patient regarding the publication of the case report.

\section{CONSENT OF PARTICIPANTS}

Written consent for participation in the study as well as for the publication of data were taken from the patient.

\section{FUNDING}

None.

\section{CONFLICT OF INTEREST}

The authors declare no conflict of interest, financial or otherwise.

\section{ACKNOWLEDGEMENTS}

Declared none.

\section{REFERENCES}

[1] Headache Classification Committee of the International Headache Society (IHS)The international classification of headache disorders. 2013.

[2] Pareja JA, Caballero V, Sjaastad O. SUNCT syndrome. Statuslike pattern. Headache 1996; 36(10): 622-4.

[http://dx.doi.org/10.1046/j.1526-4610.1996.3610622.x] [PMID: 8990604]

[3] Levy A, Matharu MS. Short-Lasting Unilateral Neuralgiform Headache Attacks. Ann Indian Acad Neurol 2018; 21(Suppl. 1): S31-8.

[http://dx.doi.org/10.4103/aian.AIAN 356 17] [PMID: 29720816]

[4] Lambru G, Matharu MS. SUNCT and SUNA: medical and surgical treatments. Neurol Sci 2013; 34(Suppl. 1): S75-81. [http://dx.doi.org/10.1007/s10072-013-1366-0] [PMID: 23695051]

[5] Costa A, Antonaci F, Ramusino MC, Nappi G. The Neuropharmacology of Cluster Headache and other Trigeminal Autonomic Cephalalgias. Curr Neuropharmacol 2015; 13(3): 304-23. [http://dx.doi.org/10.2174/1570159X13666150309233556] [PMID: 26411963]

[6] Sjaastad O, Saunte C, Salvesen R, et al. Shortlasting unilateral neuralgiform headache attacks with conjunctival injection, tearing, sweating, and rhinorrhea. Cephalalgia 1989; 9(2): 147-56. [http://dx.doi.org/10.1046/j.1468-2982.1989.902147.x] [PMID: 2743414]

[7] Montes E, Alberca R, Lozano P, Franco E, Martínez-Fernández E, Mir
P. Statuslike SUNCT in two young women. Headache 2001; 41(8): 826-9.

[http://dx.doi.org/10.1046/j.1526-4610.2001.01151.x] [PMID: 11576210]

[8] Williams MH, Broadley SA. SUNCT and SUNA: clinical features and medical treatment. J Clin Neurosci 2008; 15(5): 526-34.

[http://dx.doi.org/10.1016/j.jocn.2006.09.006] [PMID: 18325769]

[9] Chowdhury Debashish, et al. Dramatic Response of Intravenous Lidocaine in a Patient with Status like SUNA: A Case Report and Brief Review of Literature. Cephalalgia Reports, 2018.Jan [http://dx.doi.org/10.1177/2515816318804816]

[10] Cao Y, Yang F, Dong Z, Huang X, Cao B, Yu S. Secondary ShortLasting Unilateral Neuralgiform Headache with Conjunctival Injection and Tearing: A New Case and a Literature Review. J Clin Neurol 2018; 14(4): 433-43.

[http://dx.doi.org/10.3988/jcn.2018.14.4.433] [PMID: 29856156]

[11] Lambru G, Matharu MS. SUNCT, SUNA and trigeminal neuralgia: different disorders or variants of the same disorder? Curr Opin Neurol 2014; 27(3): 325-31

[http://dx.doi.org/10.1097/WCO.0000000000000090] [PMID: 24792341]

[12] Benoliel R. Trigeminal autonomic cephalgias. Br J Pain 2012; 6(3): 106-23.

[http://dx.doi.org/10.1177/2049463712456355] [PMID: 26516482]

[13] Lambru G, Miller S, Matharu MS. The red ear syndrome. J Headache Pain 2013; 14: 83 .

[http://dx.doi.org/10.1186/1129-2377-14-83] [PMID: 24093332]

[14] Daykin H. The efficacy and safety of intravenous lidocaine for analgesia in the older adult: a literature review. Br J Pain 2017; 11(1): 23-31

[http://dx.doi.org/10.1177/2049463716676205] [PMID: 28386401]

[15] Abram SE, Yaksh TL. Systemic lidocaine blocks nerve injury-induced hyperalgesia and nociceptor-driven spinal sensitization in the rat. Anesthesiology 1994; 80(2): 383-91.

[http://dx.doi.org/10.1097/00000542-199402000-00018] [PMID 8311320]

[16] McCarthy GC, Megalla SA, Habib AS. Impact of intravenous lidocaine infusion on postoperative analgesia and recovery from surgery: a systematic review of randomized controlled trials. Drugs 2010; 70(9): 1149-63.

[http://dx.doi.org/10.2165/10898560-000000000-00000] [PMID 20518581]

[17] Eijkelkamp N, Linley JE, Baker MD, et al. Neurological perspectives on voltage-gated sodium channels. Brain 2012; 135(Pt 9): 2585-612. [http://dx.doi.org/10.1093/brain/aws225] [PMID: 22961543]

[18] Amaya F, Wang H, Costigan M, et al. The voltage-gated sodium channel $\mathrm{Na}(\mathrm{v}) 1.9$ is an effector of peripheral inflammatory pain hypersensitivity. J Neurosci 2006; 26(50): 12852-60.

[http://dx.doi.org/10.1523/JNEUROSCI.4015-06.2006]

[PMID: 17167076]

[19] Liu PhD Min, N John, PhD, FRSN Wood. The Roles of Sodium Channels in Nociception: Implications for Mechanisms of Neuropathic Pain, Pain Medicine 2011; (suppl_3)(12): S93-9.

[20] Cummins TR, Rush AM. Voltage-gated sodium channel blockers for the treatment of neuropathic pain. Expert Rev Neurother 2007; 7(11): 1597-612.

[http://dx.doi.org/10.1586/14737175.7.11.1597] [PMID: 17997706]

[21] Weinberg L, Peake B, Tan C, Nikfarjam M. Pharmacokinetics and pharmacodynamics of lignocaine: A review. World J Anesthesiol 2015; 4(2): 17-29.

[http://dx.doi.org/10.5313/wja.v4.i2.17]

[22] Lee JM, Yan P, Xiao Q, et al. Methylprednisolone protects oligodendrocytes but not neurons after spinal cord injury. J Neurosci 2008; 28(12): 3141-9.

[http://dx.doi.org/10.1523/JNEUROSCI.5547-07.2008] [PMID: 18354017]

[23] McDaneld LM, Fields JD, Bourdette DN, Bhardwaj A Immunomodulatory therapies in neurologic critical care. Neurocrit Care 2010; 12(1): 132-43.

[http://dx.doi.org/10.1007/s12028-009-9274-0] [PMID: 19774497]

[24] Frohman EM, Stüve O, Havrdova E, et al. Therapeutic considerations for disease progression in multiple sclerosis: evidence, experience, and future expectations. Arch Neurol 2005; 62(10): 1519-30. [http://dx.doi.org/10.1001/archneur.62.10.1519] [PMID: 16216934]

[25] Kawada S, Kashihara K, Imamura T, Ohno M. High-dose intravenous methylprednisolone for the prophylactic treatment of cluster headache. Springerplus 2013; 2(1): 156 
[http://dx.doi.org/10.1186/2193-1801-2-156] [PMID: 23667809]

[26] Coutinho AE, Chapman KE. The anti-inflammatory and immunosuppressive effects of glucocorticoids, recent developments and mechanistic insights. Mol Cell Endocrinol 2011; 335(1): 2-13. [http://dx.doi.org/10.1016/j.mce.2010.04.005] [PMID: 20398732]

[27] Liberman AC, Budziñski ML, Sokn C, Gobbini RP, Steininger A, Arzt E. Regulatory and Mechanistic Actions of Glucocorticoids on T and Inflammatory Cells. Front Endocrinol (Lausanne) 2018; 9: 235

[http://dx.doi.org/10.3389/fendo.2018.00235] [PMID: 29867767]

[28] Sloka JS, Stefanelli M. The mechanism of action of methylprednisolone in the treatment of multiple sclerosis. Mult Scler 2005; 11(4): 425-32.

[http://dx.doi.org/10.1191/1352458505ms1190oa] [PMID: 16042225]

[29] Jongen PJ, Stavrakaki I, Voet B, et al. Patient-reported adverse effects of high-dose intravenous methylprednisolone treatment: a prospective web-based multi-center study in multiple sclerosis patients with a relapse. J Neurol 2016; 263(8): 1641-51.

[http://dx.doi.org/10.1007/s00415-016-8183-3] [PMID: 27272956]

[30] Min KH, Rhee CK, Jung JY, Suh MW. Characteristics of adverse effects when using high dose short term steroid regimen. Korean J Audiol 2012; 16(2): 65-70. [http://dx.doi.org/10.7874/kja.2012.16.2.65] [PMID: 24653873]

[31] Odabas AR, Cetinkaya R, Selcuk Y, Kaya H. Severe arthralgia and myalgia due to high-dose methylprednisolone pulse therapy cured by potassium infusion in a patient with diffuse proliferative lupus nephritis. Nephron 2001; 87(1): 95.

[http://dx.doi.org/10.1159/000045893] [PMID: 11174035]

[32] Stanbury RM, Graham EM. Systemic corticosteroid therapy--side effects and their management. Br J Ophthalmol 1998; 82(6): 704-8. [http://dx.doi.org/10.1136/bjo.82.6.704] [PMID: 9797677]

[33] Du Y, Mou Y, Liu J. Efficiency evaluation and safety monitoring of tailored rapid potassium supplementation strategy for fatal severe hypokalemia. Exp Ther Med 2019; 17(4): 3222-32.

[http://dx.doi.org/10.3892/etm.2019.7292] [PMID: 30936997]

[34] Bogorad I, Blum S, Green M. A case of MS presenting with SUNCT status. Headache 2010; 50(1): 141-3.

[http://dx.doi.org/10.1111/j.1526-4610.2009.01514.x] 19751367]

[35] Matharu MS, Cohen AS, Goadsby PJ. SUNCT syndrome responsive to intravenous lidocaine. Cephalalgia 2004; 24(11): 985-92.

[http://dx.doi.org/10.1111/j.1468-2982.2004.00886.x] 15482363]

\section{(C) 2020 Gurumukhani et al.}

This is an open access article distributed under the terms of the Creative Commons Attribution 4.0 International Public License (CC-BY 4.0), a copy of which is available at: https://creativecommons.org/licenses/by/4.0/legalcode. This license permits unrestricted use, distribution, and reproduction in any medium, provided the original author and source are credited. 